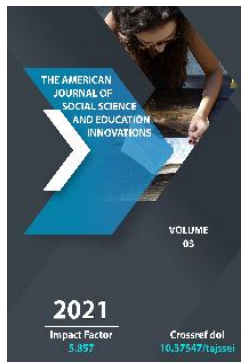

\title{
Development Of Creative Abilities In The Lessons Of The Russian Language In The Front Of Applying The Technology Of Developing Critical Thinking Through Reading And Writing
}

\author{
Abdurahmonova Dilbarxon \\ Namangan Institute Of Engineering And Technology Senior Teacher, Namangan, Uzbekistan
}

Journal Website:

http://theamericanjour

nals.com/index.php/taj

ssei

Copyright: Original content from this work may be used under the terms of the creative commons attributes

\section{ABSTRACT}

The article describes the complex tasks of upbringing and development of the individual in modern conditions, the content of the application of technologies for the development of their creative abilities, critical thinking through reading and writing in Russian lessons.

\section{KEYWORDS}

Personality, upbringing, critical thinking, creative ability, reading, writing, adaptation problem.

\section{INTRODUCTION}

The development and education of the individual in modern conditions is a complex task. One of the urgent problems associated with the success of training is the problem of adaptation. Successful adaptation is the main factor in the optimization of educational activities, a condition for the all-round development of the personality, the 
preservation of mental and somatic health. By maladjustment, which entails serious problems, we mean a certain set of signs that indicate the discrepancy between the psychophysical, personal and sociopsychological characteristics of the child and the requirements of the situation.

It is absolutely clear that each child is individual and unique due to the uniqueness of his natural characteristics. The process of its development, transformation into a psychologically mature and morally fullfledged member of society should be carried out under the influence of education and training. The modern school is in search of such models of education and upbringing that can provide a diversified development of the child's personality. The school should be focused on an adaptive model that provides students with the right to choose the level of learning complexity. The motivational and personal aspect of adaptation is associated with the formation of positive educational motives and personal qualities of the student.

Modern society, more than ever, requires an intellectually developed, active personality. For its further development, our country needs people capable of reproducing not only the material, but also the intellectual potential of Uzbekistan. A school graduate must think independently, be able to see the difficulties arising in the real world and look for ways to overcome them.

Pedagogical practice has shown that there are a number of problems, without the solution of which it is impossible to ensure the productive development of the child's intellectual abilities. First, the observations carried out among students showed that many do not have a reading culture, do not know how to read thoughtfully, do not highlight the main thing, do not reflect on the information received. Secondly, it is difficult to work with rules and tables. As a rule, students voice statistics without analyzing them, without highlighting cause-and-effect relationships. Thirdly, in most cases, students, especially in grades 5-6, are not always able to answer problematic paraphrased questions. Fourth, information is increasingly recognized as an important pedagogical resource.

At the present stage, students should, according to the psychologist V. Stern, "consciously adjust their thinking to the requirements that have arisen." Such "tuning" is impossible without the ability to use various sources of information: from the teacher's words to the "worldwide network". The use of techniques of critical thinking technology can help in solving these problems and in creating conditions that maximally stimulate the development of intellectual abilities, since critical thinking is one of the types of human intellectual activity, which is characterized by a high level of perception, understanding, objectivity of the approach to the information surrounding him field.

As you know, in order to provide a new quality of education, the teacher needs effective pedagogical technologies. In my work I use technologies such as the gradual formation of mental actions, level differentiation, the technology for the development of critical thinking, since they allow to implement the principle of an oriented approach in learning, are health-saving. The use of the technology of level differentiation increases the efficiency of the implementation of the requirements of the educational standard, allows for an objective assessment of students on a tenpoint system.

The technology for the development of critical thinking through reading and writing allows you to actively introduce students into the learning process, and not just transfer knowledge, makes the learning process more emotionally rich and creative. One of the aspects of the problem of internal adaptation of schoolchildren is associated with their creative abilities. Students adapt better to 
complex processes and situations through creativity. The technology for the development of critical thinking allows you to create a creative atmosphere. A positive attitude towards oneself and one's abilities in language lessons, faith in oneself as a student, the ability of teachers to take into account individual characteristics - these are the conditions for ensuring an adaptive environment.

The technology of developing critical thinking through reading and writing is closely related to the concept of student-centered learning. In the process of applying this technology, general educational skills are developed, the ability to work in a group, the ability to creatively interpret information, conditions are created for variability and differentiation of training. And most importantly, in the lessons using this technology, the guys feel comfortable, everyone chooses a task according to their strength. This is a universal "supra-subject" technology, open to dialogue with other pedagogical approaches. The technology is based on a basic model consisting of three phases: challenge, realization of meaning, reflection. The first phase (challenge) is focused on the actualization of existing knowledge, the formation of personal interest in obtaining new information. Since this combines individual and group forms of work, the participation of trainees in the educational process is intensified. This creates the conditions for success. This is especially important in grades 5, since this period of child development is defined as a crisis, difficult for a student.

The main tasks of the second phase (realization of meaning) are the active acquisition of information, systematization, tracking their own understanding. The student gets the opportunity to think about the nature of the object being studied, as the old and new information is correlated, he learns to formulate questions, to determine his own position. Under the guidance of the teacher and with the help of his peers, the child will answer the questions that he himself posed for himself in the first stage. For example, the "advanced lecture" technique is active listening, partnerships, and the development of social competence. Using this technique allows you to turn the teacher's story into an interesting dialogue between student and student, student with teacher and the whole class. The third phase (reflection) is aimed at systematizing new information, developing one's own attitude towards what is being studied.

The problem of insufficient reflection in school does not provide an opportunity for personal awareness of the material, one's own actions and thoughts. This problem is eliminated by the techniques of oral and written reflection. Oral reflection teaches you to publicly formulate and indicate your attitude to the subject. Written reflection will allow students to be alone with their thoughts, teach internal dialogue, deepen the inner world and develop communicative reflection, i.e. reflection for another. Drawing up essays, various types of essays, poems based on the model allows the student's creative abilities to be revealed more widely.

\section{REFERENCES}

1. Zaprudskiy N. I. Modern school technologies - 2 / N. And. Zaprudsky Minsk: Sir-Vit, 2010.

2. Kolechenko A.K. Encyclopedia of pedagogical technologies / A.K. Kolechenko - Saint Petersburg: Karo, 2011.

3. Murina L. A. Methodology of the Russian language in the school of Belarus / L.A. Murina. - Minsk: Universitetskoe, 1990 .-$145 \mathrm{p}$. 